\title{
Male offspring of both diabetic parents have higher insulin resistance and serum leptin levels compared to those with one diabetic parent
}

\author{
Adeela Shahid, Khalid P. Lone, Sadia Saeed, Muhammad Arslan \\ Centre for Research in Endocrinology and Reproductive Sciences, University of Health Sciences, Lahore, Pakistan \\ This study was supported by a research grant from the Higher Education Commission, Pakistan
}

\begin{abstract}
OBJECTIVE: We studied the influence of positive family history (FH) of type 2 diabetes mellitus (T2DM) in male offspring using multiple metabolic and endocrine parameters in order to assess whether one or more of these parameters can be used as indicators for T2DM development later in life. DESIGN: Fifty male subjects with one diabetic parent (ODP) and thirty with both diabetic parents (BDP) were compared with fifty, age-matched, offspring of non-diabetic parents (NDP). Body weight, height, BMI and blood pressure were determined in all subjects. Fasting blood samples were analyzed for glucose, HbA1-c, insulin, C-peptide, leptin and lipid profile. A $2 \mathrm{~h}$ oral glucose tolerance test (2h-OGTT) was also carried out. Insulin resistance (IR) was assessed by HOMA-IR index. RESULTS: Mean serum levels of glucose (fasting and following $2 \mathrm{~h}$-OGTT), C-peptide and leptin in male offspring of diabetic parents were higher than in male offspring of NDP. Mean fasting serum insulin and triglycerides were higher in boys of BDP compared to those of ODP and NDP. HOMA-IR was markedly high in ODP and BDP groups when compared with the NDP group. No stastically significant difference was observed in the HbA1-c values between any of the groups studied. CONCLUSIONS: These results indicate that T2DM associated risk factors are more vigorously expressed in male offspring with a history of diabetes in both parents, thus underscoring the importance of genetic determinants in the onset of T2DM. The results of this study may provide useful indicators of potential susceptibility to T2DM at an early stage of life.
\end{abstract}

Key words: Diabetes, Family history, Insulin resistance, Leptin

Address for correspondence:

Muhammad Arslan, Centre for Research in Endocrinology and Reproductive Sciences, Department of Physiology and Cell Biology, University of Health Sciences,

Lahore 54600, Pakistan,

Tel.: +92 3004745668; +92 429231304; Fax: +92 429230370

e-mail: arslan_m2000@yahoo.com

Received 20-06-08, Revised 20-08-08, Accepted 10-09-08

\section{INTRODUCTION}

Type 2 diabetes mellitus (T2DM) includes monogenic and polygenic forms. ${ }^{1}$ Maturity onset diabetes of the young (MODY), which in most cases is a monogenic form of the disease, has an autosomal dominant mode of inheritance. ${ }^{2}$ The polygenic form of diabetes has a complex pathophysiology and the 
multiple genes involved are known to produce insulin resistance and a variable degree of $\beta$-cell dysfunction. ${ }^{3}$ Studies in offspring of type 2 diabetic parents demonstrate that insulin resistance most likely has a primary role in the development of T2DM because of its presence 1-2 decades before the diagnosis of disease. ${ }^{4-6}$

In a number of ethnic groups, obesity is associated with evidence of insulin resistance and impaired insulin secretion. ${ }^{7}$ Plasma concentration of adipose tissue metabolites, leptin and non-esterified fatty acids are shown to be higher in insulin resistant Asian Indians as compared to more insulin sensitive Caucasians. ${ }^{8}$ Leptin has been regarded as a key molecule in the insulin signaling pathways that may be associated with the development of obesity, insulin resistance and diabetes at a later stage in life. ${ }^{9}$ Also, peripheral leptin levels have been shown to be elevated in insulin resistant type 2 diabetics, independent of body composition. ${ }^{10}$ The higher plasma leptin found in offspring of diabetic mothers may play a significant role in the development of hyperinsulinemia and subsequent insulin resistance in children. ${ }^{11}$ Available data therefore suggest that leptin levels may serve as a useful marker of T2DM risk in children and young adults. $^{12}$

Evidence is available indicating that siblings of diabetic parents are at increased risk of developing diabetes, and the risk increases if grandparents are also diabetic. ${ }^{13,14}$ In a study among Pima Indians, the incidence of the disease was shown to be highest if both parents were diabetic. ${ }^{15}$ Furthermore, several studies, mainly in adults, have shown that family history $(\mathrm{FH})$ of T2DM is associated with hyperinsulinemia. ${ }^{16-18}$

In spite of the abundance of adult data, relatively few studies have focused on the impact FH of T2DM on parameters of carbohydrate and lipid metabolism at an early age..$^{19-21}$ The present study was undertaken to evaluate differences, if any, in the risk factors for development of T2DM in offspring with one or both type 2 diabetic parents, using a number of metabolic and endocrine indicators in Pakistani (Southeast Asian) male subjects. It is expected that the present investigation may provide useful leads to an early diagnostic regimen and better management of diabetes-prone individuals at an early age.

\section{SUBJECTS AND METHODS}

The present study, based on a total of 130 Southeast Asian male subjects aged $15-25$ years (mean \pm SD $20.66 \pm 0.57$ ), was approved by the Ethical Committee and the Research Board of the University of Health Sciences, Lahore.

The study subjects, who underwent a detailed medical examination, had fasting blood glucose levels $(\mathrm{FBG})<6.9 \mathrm{mmol} / \mathrm{L}^{22}$ and no signs of acute or chronic illness. All participants and their parents were asked to complete a questionnaire on their FH of diabetes and any other major disease such as cardiovascular and autoimmune diseases, as well as on their life-style characteristics (e.g. physical activity, dietary habits, smoking, economic status). Subjects with a history of T1DM in either of the parents, on medications known to affect body growth or lipid metabolism, with endocrinopathies or any major illness since birth, were excluded from the study. None of the subjects were the product of diabetic pregnancy.

\section{Study Design}

This is a cross-sectional study and the subjects were divided into the following 3 age-matched groups:

- Group I: Offspring of one parent with T2DM $(\mathrm{ODP})(\mathrm{n}=50$; mean age $\pm \mathrm{SD}: 19.52 \pm 0.46 \mathrm{y})$

- Group II: Offspring of both parents with T2DM (BDP) $(n=30$; mean age \pm SD: $21.28 \pm 0.59 y)$

- Group III: Offspring without a family history of DM (NDP) $(n=50$; mean age \pm SD: 21.18 $\pm 0.40 y)$.

\section{Physical Measurements and Blood Collection}

Body weight (BW), height, blood pressure and body mass index (BMI) were recorded for all patients. Six $\mathrm{ml}$ of venous blood was drawn from the cubital vein after overnight fasting of $12 \mathrm{~h}$ for analytical purposes. The-two hour oral glucose tolerance test (2h-OGTT) was carried out to evaluate the glucose tolerance status according to the procedure recommended by WHO ${ }^{23}$ All subjects were put on a diet containing at least $150 \mathrm{gm}$ of carbohydrates for 3 days prior to OGTT. In all cases blood was withdrawn between 0800-0900 h. Blood glucose levels were measured the same day. The remaining serum sample was aliquoted and stored at $-80^{\circ} \mathrm{C}$ until used. 


\section{Analytical Determinations}

All biochemical parameters were determined in duplicate using standard procedures. The diabetic condition or otherwise of parents was reconfirmed by determining FBG levels. Parents who had FBG $\geq 6.9 \mathrm{mmol} / \mathrm{L}$ were labeled as diabetic. ${ }^{22}$ Serum glucose levels were determined by the glucose oxidase method using a commercial reagent kit (RANDOX Laboratories, Crumlin, UK). Fasting lipid profile was obtained by measuring serum triglycerides (TG) by the GPO-PAP method (RANDOX), HDL- and LDL-cholesterol by a direct quantitative method (Roche Diagnostics GmbH, Mannheim, Germany) and cholesterol by an enzymatic method (RANDOX). The estimations were made with a HumaStar 180 chemistry analyzer (Human, Wiesbaden, Germany). HbA1-c was estimated by affinity liquid chromatography with a D-SI Glycomat (Provalis Diagnostics, Deeside, UK).

\section{Hormone Assays}

Serum insulin and leptin concentrations were determined by ELISA using commercial kits (insulin: Monobind Inc, Lake Forest, CA, USA; leptin: Diagnostic System Laboratories, Inc, Webster, TX, USA) with an automated EIA analyzer (Bio-Rad Laboratories, Hercules, CA, USA). Peripheral Cpeptide levels were measured with a specific immunoradiometric assay (IRMA; Immunotech a.s., Prague, Czech Republic) using an automatic gamma counter (Perkin Elmer, Turku, Finland).

\section{Insulin resistance index}

Fasting glucose and fasting insulin levels were used to measure homeostasis model assessment of insulin resistance (HOMA-IR) index by the formula:

HOMA-IR $=$ Fasting insulin $(\mu \mathrm{IU} / \mathrm{ml}) \times$ Fasting glucose $(\mathrm{mmol} / \mathrm{l}) / 22.5 .{ }^{24}$

\section{Statistical Analysis}

The significance of differences among the three groups was analyzed by-one way ANOVA followed by Scheffe's multiple comparisons. The Pearson test was used to calculate correlation between variables of interest. P value $<0.05$ was considered statistically significant. All calculations were carried out with the SPSS version 12 (SPSS, Inc, Chicago, IL, USA).

\section{RESULTS}

\section{Body Weight, BMI and Blood Pressure}

The body weight (BW) of offspring of BDP was significantly higher $(\mathrm{P}=0.015)$ than those of NDP but there was no significant difference in the $\mathrm{BW}$ of offspring of ODP and the control (NDP) group. However, the mean BMI of both groups of offspring of diabetic parents was significantly greater than that of offspring of NDP (Tables 1 and 3). The proportion of overweight ${ }^{25}$ offspring was $4 \%, 34 \%$ and $45 \%$ in NDP, ODP and BDP groups, respectively. Although no significant difference was observed in the systolic BP of offspring of ODP and NDP, the mean systolic $\mathrm{BP}$ was slightly but significantly higher in offspring of $\mathrm{BDP}$ as compared to that of the ODP $(\mathrm{P}=0.002)$ and NDP $(\mathrm{P}=0.034)$ (Tables 1 and 3$)$. In $21 \%$ of the offspring of BDP the systolic and diastolic BP were above the normal range of $130 / 80 \mathrm{~mm} \mathrm{Hg} .{ }^{22}$

\section{Glucose, 2-h OGTT and Hb A1-c}

Although the mean fasting glucose levels and the following OGTT were in the normal range of subjects, the mean FBG levels were significantly higher in the ODP and BDP offspring than in the NDP group (Tables 2 and 3). Blood glucose concentrations following fasting were $>5.6$ and $<6.9 \mathrm{mmol} / \mathrm{L}^{22}$ in $2 \%$ of offspring of NDP, $34 \%$ of ODP and $37 \%$ of BDP, respectively. Blood glucose levels at 2-h following oral glucose administration (2h-OGTT) were also significantly higher $(\mathrm{P}=0.001)$ in offspring of diabetic parents compared to those of NDP (Tables 2 and 3 ). In the present study, $24 \%$ offspring of BDP and $20 \%$ offspring of ODP had impaired glucose tolerance

Table 1. Physical characteristics of offspring of non-diabetic (NDP), one diabetic (ODP) and both diabetic (BDP) parents. Data are expressed as means \pm SEM

\begin{tabular}{lccc}
\hline & $\begin{array}{c}\text { NDP } \\
(\mathbf{n = 5 0})\end{array}$ & $\begin{array}{c}\text { ODP } \\
(\mathbf{n = 5 0})\end{array}$ & $\begin{array}{c}\text { BDP } \\
(\mathbf{n = 3 0})\end{array}$ \\
\hline Body weight $(\mathrm{kg})$ & $62.1 \pm 1.7$ & $66.8 \pm 2.7$ & $74.3 \pm 4.3^{\mathrm{a}}$ \\
BMI $\left(\mathrm{kg} / \mathrm{m}^{2}\right)$ & $21.4 \pm 0.5$ & $24.7 \pm 0.9^{\mathrm{a}}$ & $27.4 \pm 1.7^{\mathrm{a}}$ \\
Systolic BP $(\mathrm{mmHg})$ & $110.4 \pm 1.2$ & $107.4 \pm 1.6$ & $118.6 \pm 3.8^{\mathrm{a}, \mathrm{b}}$ \\
Diastolic BP $(\mathrm{mmHg})$ & $71.8 \pm 1.3$ & $70.1 \pm 1.3$ & $73.5 \pm 2.0$ \\
Acanthosis nigricans $(\%)$ & 0 & 0 & 31 \\
\hline
\end{tabular}

${ }_{\mathrm{a}, \mathrm{b}}$ Statistically significant difference $(\mathrm{P}<0.05$; Scheffe's multiple comparison test): ${ }^{\text {a: }}$ Compared to NDP group, ${ }^{\text {b: }}$ Compared to ODP group. 
Table 2. Biochemical data of offspring of non-diabetic (NDP), one diabetic (ODP) and both diabetic (BDP) parents. Data are expressed as means \pm SEM.

\begin{tabular}{lccc}
\hline & $\begin{array}{c}\text { NDP } \\
(\mathbf{n = 5 0})\end{array}$ & $\begin{array}{c}\text { ODP } \\
(\mathbf{n = 5 0})\end{array}$ & $\begin{array}{c}\text { BDP } \\
(\mathbf{n = 3 0})\end{array}$ \\
\hline $\begin{array}{l}\text { Fasting Glucose } \\
\text { (mmol/L) }\end{array}$ & $4.63 \pm 0.07$ & $5.27 \pm 0.09^{\mathrm{a}}$ & $5.32 \pm 0.12^{\mathrm{a}}$ \\
2h-OGTT (mmol/L) & $5.41 \pm 0.15$ & $6.51 \pm 0.19^{\mathrm{a}}$ & $6.69 \pm 0.35^{\mathrm{a}}$ \\
Hb A1-c (\%) & $5.34 \pm 0.05$ & $5.35 \pm 0.06$ & $5.54 \pm 0.12$ \\
Insulin (pmol/L) & $53.86 \pm 3.66$ & $66.92 \pm 4.97$ & $90.05 \pm 9.54^{\mathrm{a}, \mathrm{b}}$ \\
HOMA IR & $1.67 \pm 0.12$ & $2.4 \pm 0.19^{\mathrm{a}}$ & $3.17 \pm 0.38^{\mathrm{a}}$ \\
C-peptide (pmol/L) & $480 \pm 23.90$ & $675 \pm 50.69^{\mathrm{a}}$ & $810 \pm 101.36^{\mathrm{a}}$ \\
Leptin (ng/ml) & $4.07 \pm 0.80$ & $12.73 \pm 2.74^{\mathrm{a}}$ & $15.84 \pm 4.02^{\mathrm{a}}$ \\
$\begin{array}{l}\text { Total Cholesterol } \\
\text { (mmol/L) }\end{array}$ & $4.40 \pm 0.09$ & $3.72 \pm 0.12^{\mathrm{a}}$ & $4.76 \pm 0.20^{\mathrm{b}}$ \\
$\begin{array}{l}\text { LDL-C (mmol/L) } \\
\text { HDL-C (mmol/L) }\end{array}$ & $2.64 \pm 0.07$ & $2.30 \pm 0.08^{\mathrm{a}}$ & $2.88 \pm 0.11^{\mathrm{b}}$ \\
$\begin{array}{l}\text { Triglycerides } \\
\text { (mmol/L) }\end{array}$ & $1.22 \pm 0.03$ & $1.11 \pm 0.03^{\mathrm{a}}$ & $1.23 \pm 0.05^{\mathrm{b}}$ \\
\hline $\begin{array}{l}\text { a,b } \text { Statistically significant difference }\left(\mathrm{P}<0.05 ; \text { Scheffe's multiple }^{\prime}\right. \\
\text { comparison test): }{ }^{\mathrm{a}}: \text { Compared to NDP group, }{ }^{\mathrm{b}}: \text { Compared to } \\
\text { ODP group. }\end{array}$ & $1.66 \pm 0.07$ & $2.81 \pm 0.45^{\mathrm{a}, \mathrm{b}}$ \\
& & & \\
\hline
\end{tabular}

$(\mathrm{IGT})^{22}$ vs only $2 \%$ offspring of NDP. No statistically significant difference in the HbA1-c values was observed between the three groups.

\section{Insulin, C-Peptide and HOMA-IR}

Mean fasting insulin concentrations were significantly higher in offspring of BDP as compared to those of NDP but no statistically significant difference in mean insulin concentration was found between NDP and ODP groups. The insulin resistance as assessed by HOMA-IR was markedly higher in the ODP and BDP group as compared to the control group (Tables 2 and 3). The mean serum C-peptide levels in offspring of diabetic parents (ODP and BDP groups) were also significantly greater $(\mathrm{P}=0.026$ and $\mathrm{P}<0.001$, respectively) than in the control group (Tables 2 and 3). Fasting C-peptide concentrations were higher than $630 \mathrm{pmol} / \mathrm{ml}^{26}$ in $18 \%$ of offspring of NDP, $47 \%$ of ODP and $55 \%$ of BDP.

\section{Lipid Profile and Serum Leptin}

Mean serum TG concentrations were significantly higher in offspring of BDP as compared to those of
Table 3. Significance levels of multiple pairwise comparison (Scheffe's test) of physical and biochemical characteristics of offspring of non-diabetic (NDP), one diabetic (ODP) and both diabetic (BDP) parents.

\begin{tabular}{|c|c|c|c|}
\hline & $\begin{array}{l}\text { NDP vs ODP } \\
\text { P-value }\end{array}$ & $\begin{array}{l}\text { NDP vs BDP } \\
\text { P-value }\end{array}$ & $\begin{array}{l}\text { ODP vs BDP } \\
\text { P-value }\end{array}$ \\
\hline Body weight (kg) & 0.426 & 0.015 & 0.199 \\
\hline $\operatorname{BMI}\left(\mathrm{kg} / \mathrm{m}^{2}\right)$ & 0.029 & $<0.001$ & 0.206 \\
\hline $\begin{array}{l}\text { Systolic BP } \\
(\mathrm{mmHg})\end{array}$ & 0.517 & 0.034 & 0.002 \\
\hline $\begin{array}{l}\text { Diastolic BP } \\
(\mathrm{mmHg})\end{array}$ & 0.669 & 0.782 & 0.338 \\
\hline $\begin{array}{l}\text { Fasting Glucose } \\
(\mathrm{mmol} / \mathrm{L})\end{array}$ & $<0.001$ & $<0.001$ & 0.937 \\
\hline $\begin{array}{l}\text { 2h-OGTT } \\
(\mathrm{mmol} / \mathrm{L})\end{array}$ & 0.001 & 0.001 & 0.861 \\
\hline $\mathrm{Hb}$ A1-c $(\%)$ & 1.00 & 0.132 & 0.132 \\
\hline Insulin $(\mathrm{pmol} / \mathrm{L})$ & 0.213 & $<0.001$ & 0.028 \\
\hline HOMA IR & 0.009 & 0.009 & 1.00 \\
\hline $\begin{array}{l}\text { C-peptide } \\
(\mathrm{pmol} / \mathrm{l})\end{array}$ & 0.026 & $<0.001$ & 0.256 \\
\hline Leptin (ng/ml) & 0.006 & 0.001 & 0.647 \\
\hline $\begin{array}{l}\text { Total Cholesterol } \\
(\mathrm{mmol} / \mathrm{L})\end{array}$ & 0.001 & 0.336 & $<0.001$ \\
\hline LDL-C (mmol/L) & 0.014 & 0.246 & $<0.001$ \\
\hline HDL-C (mmol/L) & 0.039 & 0.983 & 0.045 \\
\hline $\begin{array}{l}\text { Triglycerides } \\
(\mathrm{mmol} / \mathrm{L})\end{array}$ & 0.991 & $<0.001$ & 0.001 \\
\hline
\end{tabular}

NDP and ODP (Tables 2 and 3) but not between offspring of NDP and ODP. Interestingly, mean serum total cholesterol $(\mathrm{P}=0.001), \operatorname{HDL}-\mathrm{C}(\mathrm{P}=0.039)$ and LDL-C $(\mathrm{P}=0.045)$ concentrations were slightly but significantly lower in offspring of ODP than those observed in the control group (Tables 2 and 3 ), whereas no statistically significant difference was observed in the total cholesterol, HDL-C and LDL-C between $\mathrm{BDP}$ and control group. On the other hand, serum leptin levels of the offspring of ODP and BDP were significantly higher than those of NDP (Tables 2 and 3). Significant positive correlation between BMI-leptin was observed in all three groups (Table 4). Also, significant positive correlations were found between serum leptin-insulin ( $\mathrm{P}=0.017)$ and leptin-Cpeptide $(\mathrm{P}<0.001)$ in offspring of $\mathrm{BDP}$ in contrast to 
Table 4. Intragroup correlation ( $\mathrm{r}$ and P-values) of physical and biochemical parameters of offspring of non-diabetic(NDP), one diabetic (ODP) and both diabetic (BDP) parents.

\begin{tabular}{lcccccc}
\hline & \multicolumn{2}{c}{ NDP } & \multicolumn{2}{c}{ ODP } & \multicolumn{2}{c}{ BDP } \\
Groups & $\mathbf{r}$ & $\mathbf{P}$ & $\mathbf{r}$ & $\mathbf{P}$ & $\mathbf{r}$ & $\mathbf{P}$ \\
\hline Insulin-age & -0.215 & 0.080 & 0.041 & 0.391 & 0.557 & 0.001 \\
HOMA-IR & -0.086 & 0.283 & -0.053 & 0.359 & 0.541 & 0.001 \\
- age & & & & & & \\
$\begin{array}{l}\text { Leptin - } \\
\text { BMI }\end{array}$ & 0.442 & 0.011 & $0.680<0.001$ & 0.619 & 0.001 \\
$\begin{array}{l}\text { Leptin - } \\
\text { C-peptide }\end{array}$ & 0.228 & 0.131 & 0.117 & 0.273 & $0.700<0.001$ \\
$\begin{array}{l}\text { Leptin - } \\
\text { Insulin }\end{array}$ & 0.250 & 0.109 & 0.188 & 0.165 & 0.474 & 0.017 \\
$\begin{array}{l}\text { Leptin - } \\
\text { tiglyceride }\end{array}$ & 0.202 & 0.157 & -0.064 & 0.371 & $0.670<0.001$ \\
$\begin{array}{l}\text { Leptin } \\
\text { - HOMA-IR }\end{array}$ & 0.212 & 0.155 & 0.201 & 0.153 & 0.512 & 0.010 \\
\hline
\end{tabular}

the other two groups (Table 4). Acanthosis nigricans, a dermatalogical finding, was observed in $31 \%$ of offspring of BDP while none of the subjects in the other two groups had this finding (Table 1).

\section{DISCUSSION}

Relatively few studies have been carried out in children regarding the impact of $\mathrm{FH}$ of T2DM on carbohydrate and lipid metabolism..$^{11,20,21}$ The present study in male offspring of diabetic parents (ODP and BDP) suggests the presence of certain risk factors of the disease at an early age. Some of the previous reports showing that offspring (both sexes) of diabetic mothers are overweight ${ }^{27}$ are consistent with our findings, demonstrating that $35 \%$ male offspring of ODP and $45 \%$ of BDP are overweight. In the present study, higher BMI in offspring of BDP and ODP compared to the control group may be due to relatively higher levels of insulin. Our clinical observations emphasize the genetic factors underlying a predisposition to metabolic dysfunction. Recently, a common variant in the FTO (fat, mass and obesity) gene has been identified that predisposes to diabetes through an effect on the BMI. ${ }^{28}$ It was shown that the risk of high BMI and hence of a predisposition to diabetes was additive and that individuals homozygous for this particular SNP (allele A) had a higher BMI as compared to heterozygote individuals

Approximately $36 \%$ of the offspring of diabetic parents included in the present study had impaired fasting glucose..$^{22}$ A moderately high glycemia may therefore serve as a preclinical sign of disturbed glucose metabolism and insulin resistance.

In the present study, mean serum insulin levels were higher in offspring of BDP as compared to those of ODP, and a significantly positive correlation (Table 4) between age and serum concentrations of insulin was found only in offspring of BDP, presumably indicating a progressive increase in insulin levels with age. Also, mean serum C-peptide levels were discernibly but not significantly higher in the BDP group than those of the ODP group. In contrast to our findings, a previous study in prepubertal offspring with $\mathrm{FH}$ of T2DM failed to demonstrate a significant difference in the fasting glucose and insulin levels and in insulin resistance, when compared with controls. ${ }^{20}$

Hyperinsulinemia in the offspring with BDP is consistent with previous findings, indicating that hyperinsulinemia in the offspring with a FH of T2DM may be associated with obesity. ${ }^{5,29}$ However, hyperinsulinemia may also be independently associated with a family history of T2DM, irrespective of obesity. ${ }^{17,18}$ Insulin resistance estimated by HOMA, which has been shown to correlate well with clamp methods, ${ }^{30}$ was significantly higher in offspring of diabetic parents than in offspring of non-diabetic parents. It has been suggested that increased ferritin concentration in offspring of T2DM parents may further contribute to hepatic insulin resistance in these subjects. ${ }^{5}$ In our study, a positive correlation between age and HOMA-IR (Table 4) was found in the offspring of BDP, but no such correlation was observed in NDP and ODP study groups, presumably due to progressive development of hepatic insulin resistance in these subjects.

A large number of subjects in our study with BDP had acanthosis nigricans (Table 1), which has been shown to be associated with hyperinsulinemia and IR in previous studies. ${ }^{31,32}$ In a study conducted in New Mexico, acanthosis nigricans was detected in $21 \%$ of children with a FH of T2DM and the prevalence of acanthosis nigricans was shown to be even higher in children with a higher BMI in the same study. ${ }^{33}$ 
Diagnosis of acanthosis nigricans may help in the identification of individuals at relatively high risk for T2DM.

In the offspring of BDP, insulin and C-peptide levels were robustly correlated with circulating leptin concentrations (Table 4). High leptin levels observed in offspring with a positive $\mathrm{FH}$ of T2DM are most probably due to a dysregulation of the adipo-insular axis. These data together with previous reports ${ }^{34,35}$ lend support to the notion that high leptin secretion may play a significant role in the development of hyperinsulinemia and insulin resistance leading to development of T2DM later in life. A positive correlation between insulin resistance and leptin (Table 4) was found in the offspring of BDP. It has been reported previously that leptin plays an important role in the development of insulin resistance. ${ }^{35}$ These observations suggest that increased circulating leptin values may serve as a useful marker of predisposition to T2DM among offspring of diabetic parents; however this observation needs futher verification.

A marked elevation of serum TG levels observed in the BDP group compared to the other two groups indicates increased lipolysis and resistance by the adipose tissue to relatively high levels of insulin. A positive correlation between TG and leptin levels (Table 4) was also found in the subjects of this study group, suggesting that leptin may be involved in the lipid metabolism by stimulating lipolysis, as reported in a previous study. ${ }^{36}$

Taken together, the present data on male offspring of diabetic parents suggest the presence of a number of risk factors for a predisposition to develop T2DM early in life and that some of these risk factors are more robustly expressed in offspring of BDP as compared to those of ODP. The latter observation suggests that homozygosity of genetic factors may play an important role in determining the level of predisposition to develop T2DM.

\section{REFERENCES}

1. Bell GI, Polonsky KS, 2001 Diabetes mellitus and genetically programmed defects in beta-cell function. Nature 414: 788-791.

2. Fajans SS, Bell GI, Polonsky KS, 2001 Molecular mechanisms and clinical pathophysiology of maturity-onset diabetes of the young. N Engl J Med 345: 971-980.

3. Druet C, Tubiana-Rufi N, Chevenne D, Rigal O, Polak M, Levy-Marchal C, 2006 Characterization of insulin secretion and resistance in type 2 diabetes of adolescents. J Clin Endocrinol Metab 91: 401-404.

4. Lilloja S, Mott DM, Spraul M, et al, 1993 Insulin resistance and insulin secretory dysfunction as precursor of non insulin dependent diabetes mellitus: Prospective studies of Pima Indians. N Enl J Med 329: 1988-1992.

5. Psyrogiannis A, Kyriazopoulou, V, Symeonidis A, Leotsinidis M, Vagenakis, 2003 Relative iron "overload" in offspring of patients with type 2 diabetes mellitus: a new component in the conundrum of insulin resistance syndrome. Hormones 2: 161-168.

6. Osei K, Rhinesmith S, Gaillard T, Schuster D, 2004 Impaired insulin sensitivity, insulin secretion, and glucose effectiveness predict future development of impaired glucose tolerance and type 2 diabetes in pre-diabetic African Americans: implications for primary diabetes prevention. Diabetes Care 27: 1439-1446.

7. Whincup PH, Gilg JA, Papacosta O, et al, 2002 Early evidence of ethnic differences in cardiovascular risk: Cross-sectional comparison of British South Asian and White children. BMJ 324 (7338): 635.

8. Abate N, Chandalia M, Snell PG, Grundy SM, 2004 Adipose tissue metabolites and insulin resistance in non diabetic Asian Indian men. J Clin Endocrinol and Metab 89: 2750-2755.

9. Mohamed-Ali V, Pinkney JH, Coppack SW, 1998 Adipose tissue as an endocrine and paracrine organ. Int $\mathrm{J}$ Obes Relat Metab Disord 22:1145-1158.

10. Fischer S, Hanefeld M, Haffner SM, et al, 2002 Insulin resistant patients with type 2 diabetes have higher serum leptin levels independently of body fat mass. Acta Diabetol 39: 105-110.

11. Kostalova L, Leskova L, Kapellerova A, Strbak V, 2001 Body mass, plasma leptin, glucose, insulin and C-peptide in offspring of diabetic and non diabetic mothers. Eur $\mathbf{J}$ Endocrinol 145: 53-58.

12. Chu NF, Chang, JB, Shieh SM, 2003 Plasma leptin, fatty acids and tumor necrosis factor-receptor and insulin resistance in children. Obes Res 11: 532-540.

13. Weijnen CF, Rich SS, Meigs JB, Krolewski AS, Warram JH, 2002 Risk of diabetes in siblings of index cases with Type 2 diabetes: Implications for genetic studies. Diabet Med 19: 41-50.

14. Makrilakis K, Katsilambros N, 2003 Prediction and prevention of type 2 diabetes. Hormones 2: 22-34.

15. McCance DR, Pettitt DJ, Hanson RL, Jacobsson LT, Knowler WC, Bennett PH, 1994 Birth weight and non insulin dependent diabetes: thrifty genotype, thrifty phenotype, or surviving small baby genotype? BMJ 308 : 942-945.

16. Guerrero-Romero F, Rodriguez-Moran M, 2001 Diabetes family history is associated with early insulin response, in healthy Hispanic-Mexican subjects. Gac Med Mex 137: 
529-534.

17. Rodriguez-Moran M, Guerrero-Romero F, 2001 The parental phenotype of diabetes, but not of essential hypertension is linked to the development of metabolic syndrome in Mexican individuals. Acta Diabetol 38: 8791.

18. Rodriguez-Moran M, Guerrero-Romero F, 2006 Hyperinsulinemia in healthy children and adolescents with a positive family history for type-2 diabetes. Pediatrics 118 : 1516-1522.

19. Danadian K, Balasekaran G, Lewy V, Meza MP, Robertson R, Arslanian SA, 1999 Insulin sensitivity in African-American children with and without family history of type 2 diabetes. Diabetes Care 22: 1325-1329.

20. Goran MI, Coronges K, Bergman RN, Cruz ML, Gower BA, 2003 Influence of family history type 2 diabetes on insulin sensitivity in prepubertal children. J Clin Endocrinol Metab 88: 192-195.

21. Goran MI, Bergman RN, Avila Q, et al, 2004 Impaired glucose tolerance and reduced $\beta$ cell function in overweight Latino children with a positive family history for type 2 diabetes. J Clin Endocrinol Metab 89: 207-212.

22. American Diabetes Association: Standards of medical care in diabetes, 2007 Diabetes Care 30: 4-41.

23. World Health Organization: Diabetes Mellitus: Report of a WHO study group, 1985 (Tech Rep Ser no 727) Geneva.

24. Matthews DR, Hosker JP, Rudenski AS, Naylor BA, Treacher DF, Turner RC, 1985 Homeostasis model assessment: insulin resistance and $\beta$-cell function from fasting plasma glucose and insulin concentrations in man. Diabetologia 28: 412-419.

25. World Health Organization Expert Committee on Physical status: the use and interpretation of anthropometry, 1995 (Tech Rep Ser no 854) Geneva.

26. Sacks DB 2006 Carbohydrates. In: Burtis CA, Ashwood ER, Bruns DE (eds): Teitz Text Book of Clinical Chemistry and Molecular Diagnostics, Elesvier, New Delhi; pp, 837-891.
27. Hunter WA, Cundy T, Rabone D, et al, 2004 Insulin sensitivity in the offspring of women with type 1 and type 2 diabetes. Diabetes Care 27: 1148-1152.

28. Frayling TM, Timpson NJ, Weedon MN, et al, 2007 A common variant in the FTO gene is associated with body mass index and predisposes to childhood and adult obesity. Science 316: 889-894.

29. Haffner SM, Stern MP, Miettinen H, Gingerich R, Bowsher RR, 1995 Higher proinsulin and specific insulin are both associated with a parental history of diabetes in nondiabetic Mexican-American subjects. Diabetes 44: 1156-1160.

30. Bonora E, Tragher G, Alberiche M, et al, 2000 Homeostasis model assessment closely mirrors the glucose clamp technique in the assessment of insulin sensitivity: studies in subjects with various degrees of glucose tolerance and insulin sensitivity. Diabetes Care 23: 57-63.

31. Kobaissi HA, Weigensberg MJ, Ball GD, et al, 2004 Relation between acanthosis nigricans and insulin sensitivity in overweight Hispanic children at risk for type 2 diabetes. Diabetes Care 27: 1412-1416.

32. Mukhtar Q, Cleverley G, Voorhees RE, Mcgrath JW, 2001 Prevalence of acanthosis nigricans and its association with hyperinsulinemia in New Mexico adolescents. J Adolesc Health 28: 372-376.

33. Kong AS, Williams Rl, Smith M, et al, 2007 Acanthosis nigricans and diabetes risk factors: Prevalence in young persons seen in Southwestern US primary care practices. Ann Fam Med 3: 202-208.

34. Covey SD, Wideman RD, McDonald C, et al, 2006 The pancreatic beta cell is a key site for mediating the effects of leptin on glucose homeostasis. Cell Metab 4: 291-302.

35. Zimmet P, Hodge A, Nicolson M, et al, 1996 Serum leptin concentration, obesity, and insulin resistance in Western Samoans: cross-sectional study. BMJ 313: 965-969.

36. Fruhbeck G, Aguado M, Martinez J A, 1997 In vitro lipolytic effect of leptin on mouse adipocytes: evidence for possible autocrine-paracrine role of leptin. Biochem Biophys Res Commun 240: 590-594. 